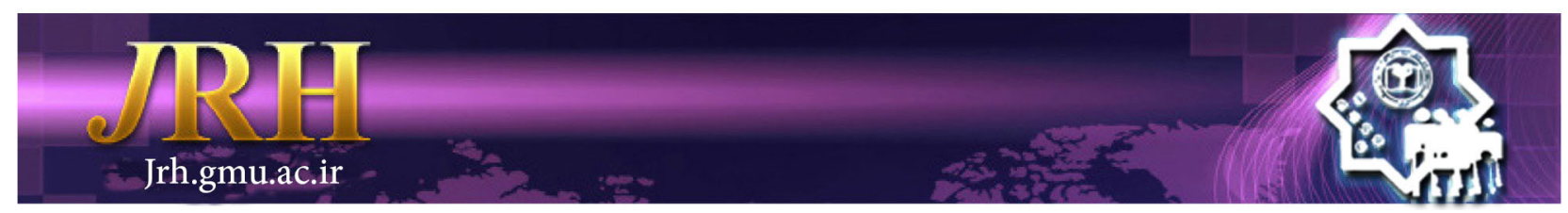

\title{
Effect of assertiveness skill training on the staffs' stress at the emergency medical center
}

Hadi Mohammadpour ${ }^{1}$, Sara Salari Dashtbayaz ${ }^{2}$, Majid Alijan

Nodehpashangi ${ }^{3}$

Journal of Research \& Health

Social Development \& Health Promotion Research Center

Vol. 8, No.6, Nov \& Dec 2018

Pages: $541-547$

DOI: 10.29252/jrh.8.6.541

Original Article

1. Correspondence to: Department of Education, School of Elementary Education, Farhangian University, Shahid Beheshti Campus, Mashhad, Iran

Email: hadi.m2008@gmail.com

2. Department of Humanities, School of Humanities, Bozorgmehr University, Qaenat, Iran

3. Department of Educational Administration, School of Management, Kharazmi University, Tehran, Iran

Received: 3 Jan 2017

Accepted: 30 Mey 2017

How to cite this article: Mohammadpour H, Salari Dashtbayaz S, Alijan Nodehpashangi M. Effect of assertiveness skill training on the staffs' stress at the emergency medical center. $J$ Research \& Health2018; 8(6): 541- 547.

\begin{abstract}
Social skills are set of learned abilities which enable individual to interact with the appreciate ability in social context. Assertiveness training skills is one of the most commonly known social skills. The purpose of this study was to investigate the role of assertiveness skill training in reducing the stress of staffs at the emergency medical center. This quasi-experimental study was carried out by using pretest and posttest with control group. The statistical population was all employees (44 participants) who working at the emergency medical center that were selected by census method and were divided into experimental group and control group. Then the assertiveness training program was conducted on the experimental group during 10 weeks (one week per session for 1.5 hours) but control group did not receive these trainings and skills. Tools included gambrill-richey assertion inventory and job stress inventory. The findings showed that the assertiveness skill training has an effect on reducing staffs' stress and increasing assertiveness at emergency medical center. Regarding the results, it can be seen that the assertiveness skill training by cognitive method will significantly increase the assertiveness and reduce the stress of the staffs and these skills enable individuals to stand up for their beliefs and rights.
\end{abstract}

Keywords: Assertiveness, Job Stress, Medical Staff, Social Skill

\section{Introduction}

Social skills are set of learned abilities that enable individual to interact with the proper ability in a social context. Assertiveness training skills is one of the most commonly known social skills [1]. Self-esteem and assertiveness skills are variables which are always interrelated closely [2]. Poop; et al. believed that a person needs to have the necessary skills to accompany others in order to feel positive about self [2].

An assertive person uses communication methods that enable to maintain self-esteem and pursue satisfaction and fulfillment of desires [3]. Those who have self-assertiveness show high levels of self-confidence and selfesteem, and low levels of stress [4].

Some people have not learned the assertive behaviors and do not have the power of "no" to say and they cannot interact assertively with people [5]. Since self-acceptance rate and self-esteem are low in these individuals [6], behaviors contrary to assertiveness interfere with person's social relationships and lead them to passive behaviors such as stress, depression and anxiety and or lead 
them to aggression and delinquency [7]. People with little or no assertiveness tend to avoid conflicts in all circumstances; these people have internalized concerns to not endanger themselves. The underlying beliefs of these people are that the needs of other people are more important than their own and if they fulfill their own needs, other people will discard them. Also, a person with low assertiveness can express thoughts and feelings in a hostile and aggressive manner. These people use threats and control to meet their needs [8].

Talking loudly and violently, looking at others with hostility, talking about past events grudgingly and humiliatingly and blamingly, spontaneous and selfish expression of feelings and beliefs in a bias pattern, giving more importance to their values than others, as well as harming others to avoid personal injury are considered as the characteristics of these individuals [9]. Therefore, in order to eliminate such behavioral disorders and emotional anomalies, it was necessary to carry out assertiveness training programs.

Assertive training is method in which efforts to increase the individuals' effect and supervision on the environment by using a variety of learning and planning programs, and by using this way, one can create the necessary field to strengthen the desired behaviors. Assertive training has been often accompanied by homework assignments and weekly planning on the activities of the authorities in the family environment, work environment and society as well as social and communication skills training. In this process, the authorities are taught to demonstrate assertive behaviors at different situations. Assertive training can be used to deal with situations and to eliminate anxiety when confronted with problems effectively [10]. Self-expression training program has several executive practices which have been applied individually or group. Some of the Self-expression training practices areas rational reconstruction, self-monitoring, resilience in the real situation, desensitization, behavior exercises, role-playing, modeling, feedback, problem solving, guidance, reinforcement, stop thinking, teaching saying "yes" or "no", expressing positive emotions, expressing negative emotions and ways to deal with criticism and constructive criticism training. It is believed that group self-expression training has more benefits than individual methods, because members of the group can practice self-expression behavior in the group. The members of the group accept expressive behaviors easily, because they understand the reasons for the behaviors, and in one group, more opportunities are offered to encourage and promote self-expression [11].

It is essential to teach self-expression skills because they can be better accepted and absorbed in the groups by gaining these skills and this increases self-esteem and consequently high self-esteem can reduce stress and increase job success. In fact, the psychological cycle begins with positive effects and its consequences also affect the self-expression [12].

It is important to perform assertiveness training programs, especially in centers such as the Emergency Medical Center which provide important services such as providing the necessary health and medical cares for all people.This study aimed to investigate the role of assertive training programs in reducing the staffs' stress at the emergency medical center of Qaen city, province south Khorasan, Iran.

\section{Method}

This quasi-experimental study was carried out by using pretest and posttest with control group. The statistical population was all employees of the emergency medical center in Qaen city (44 participants). Therefore, the census method was used due to the limited population and access to all members of the community. In order to collect information in this study, gambrill-richey assertion inventory was used to measure the participants' assertiveness and job stress inventory were used to measure job stress.

Gambrill - richey assertion inventory: It was prepared based on gambrill - richey assertion 
inventory and has 40 main items which some of the items have been modified due to lack of conformity with the Iranian culture. Each item shows a situation that requires assertiveness behavior. The participants have been asked to answer questions in terms of 5 point Likert scale. The range of scores varies from zero to 200. The gombriel \& richi's factors analysis showed that this scale has a high validity and it can distinguish between people with high and low assertiveness. Factor validity of various items of this scale is between $0.39-0.70$ and the reliability coefficients of this questionnaire have been investigated by using Cronbach's alpha and split-half method and have been reported by Gambriel and Richy 0.81 and 0.83 , respectively. The validity of the questionnaire was assessed 0.88 by Ghobary Bonab \& Hejazi with using Cronbach's alpha coefficient [13]. Steinmetz Job Stress Inventory: This inventory was developed by Steinmetz and was translated by Attar. This inventory has 36 items which examine the individual's stress on the nature of work, colleagues and head nurses [14]. The items of this scale have a 3-point response including completely correct, somewhat correct and incorrect. How to score the items in this inventory is that the phrase "completely correct", "somewhat correct" and "incorrect" have $2,1,0$ points, respectively, and the range of grades is between 0 and 72 .

After obtaining the necessary permissions from the relevant organizations and coordination with the authorities, all of participants were invited to complete the pre-test tools. Participants were randomly divided into experimental and control groups (22 participants in experimental group and 22 participants in control group). The aassertiveness program was then performed in an experimental group for 10 weeks(one week per session for 1.5 hours) but the control group did not receive these trainings and skills. The training program was conducted with the maximum possible number of participants at the emergency medical center. Regarding the working conditions, for the number of people who didn't attend the training sessions, compensation programs and educational booklets were considered. At the end of the last session, both groups were responded to posttest. The assertiveness training program is presented in Table 1.

Table1 Assertiveness training program

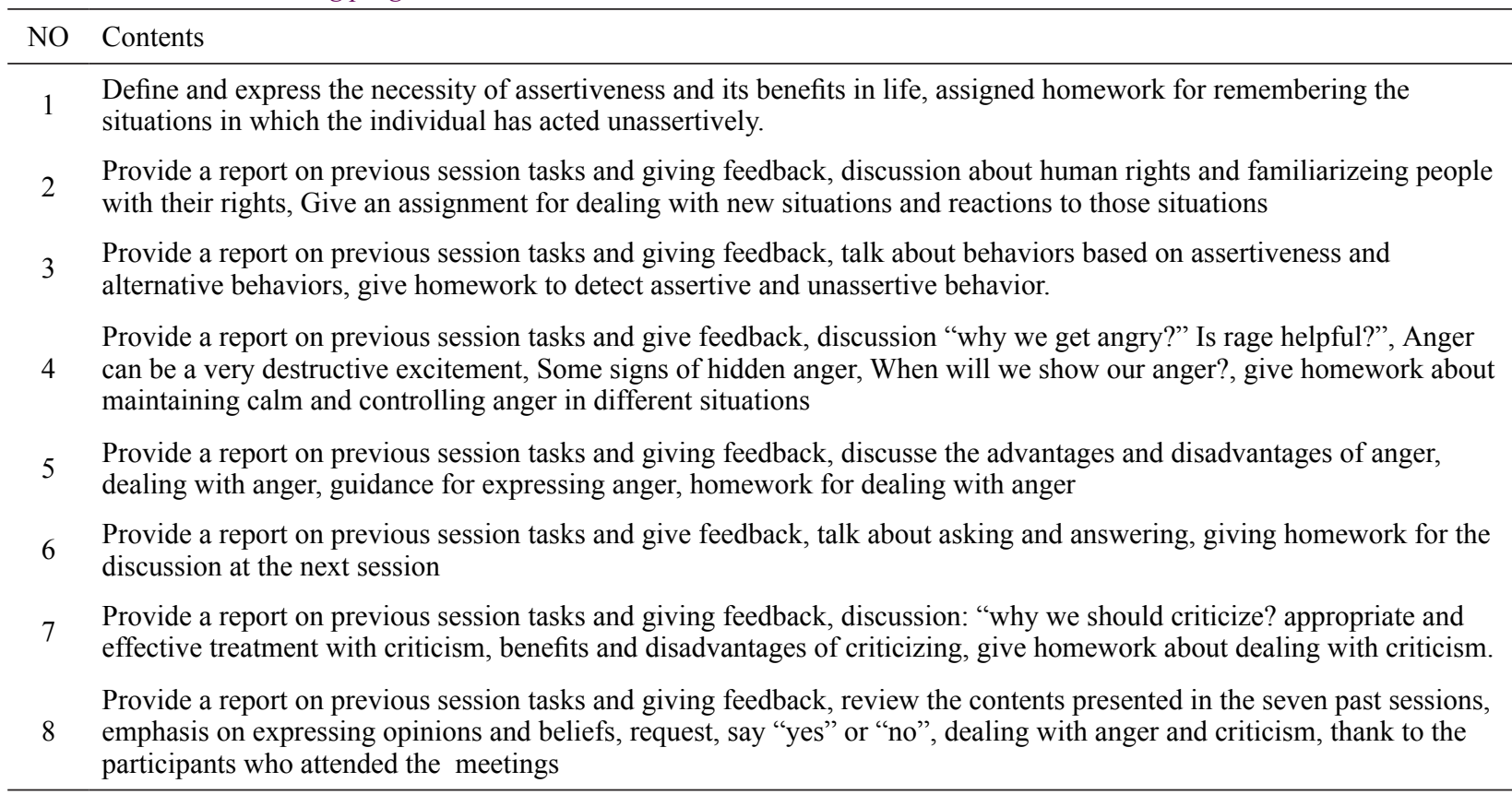

\section{Results}

Based on descriptive findings, the mean age of respondents in this study was 25.52 years with a standard deviation of 0.3 whose dispersion is between 20 and 32 years. Also, the mean work experience for these people is 4.20 years whose dispersion is between 1-9 
years. In terms of the level of education, one of the participants has a diploma, 37 have an associate's degree and 6 of the participants have a bachelor's degree.

Since the normal distribution of data is the default of covariance analysis, therefore, Kolmogorov-Smirnov test was used to check the normality of the data that the results for the stress and assertiveness test are presented in Table 2.

Table 2. Kolmogorov-smirnov test to check the normality of the stress and assertiveness statistics

\begin{tabular}{lcccc}
\hline & $\begin{array}{c}\text { Posttest } \\
\text { (stress) }\end{array}$ & $\begin{array}{c}\text { Pretest } \\
\text { (stress) }\end{array}$ & $\begin{array}{c}\text { Posttest } \\
\text { (assertiveness) }\end{array}$ & $\begin{array}{c}\text { Pretest } \\
\text { (assertiveness) }\end{array}$ \\
\hline Number & 44 & 44 & 44 & 44 \\
Mean & 24.86 & 30.84 & 125.97 & 113.68 \\
Standard deviation & 9.08 & 9.48 & 14.54 & 7.94 \\
Kolmogorov-Smirnov & 0.889 & 0.884 & 0.767 & 1.131 \\
Significance level & 0.408 & 0.416 & 0.598 & 0.155 \\
\hline
\end{tabular}

The results of the analysis of Table 2 show decreased, but the average assertiveness level that the significance level is higher than 0.05 so the normal distribution was established for the data. Also, the Table showed that the mean stress level in the pretest and posttest has has increased.

Table 3 is the interpersonal effects which show the main output of covariance analysis.

Table 3 Analyses of covariance for the effect of independent variable on employees' assertiveness

\begin{tabular}{lcccc}
\hline Change sources & df & $\begin{array}{c}\text { Mean of } \\
\text { squares }\end{array}$ & F & Sig \\
\hline $\begin{array}{l}\text { Concomitant variable (pretest } \\
\text { scores) }\end{array}$ & 1 & 5889.6 & 120.03 & 0.0001 \\
Group effect (test and control) & 1 & 1746.47 & 38.26 & 0.0001 \\
Error & 41 & 45.64 & & \\
Sum of squares & 43 & & & \\
\hline
\end{tabular}

As Table 2, considering ( $\mathrm{p}=0.001$ and $\mathrm{F}=120.03$ ), the effect of concomitant variable is significant, it means that the difference between the pretest and posttest scores is significant. By considering $(\mathrm{p}=0.001$ and $\mathrm{F}=38.26)$, group effect is significant.
It means that difference between two test and control groups is significant. In other words, assertiveness skills training have effect on the increasing of assertiveness among the staffs of emergency medical center at Qaen city.

Table 4 Analysis of covariance for effect of independent variable on staffs' stress

\begin{tabular}{lcccc}
\hline Change sources & df & $\begin{array}{c}\text { Mean of } \\
\text { squares }\end{array}$ & F & Sig \\
\hline Concomitant variable (pretest scores) & 1 & 2226.89 & 170.9 & 0.0001 \\
Group effect (test and control) & 1 & 1190.22 & 91.38 & 0.0001 \\
Error & 41 & 13.02 & & \\
Sum of squares & 43 & & & \\
\hline
\end{tabular}

As Table 4, by considering analyses of covariance $(p=0.001$ and $F=170.9)$, the effect of concomitant variable is significant; in other words, difference between the pre-test and posttest scores is significant. Considering $(\mathrm{p}=0.001$ and $\mathrm{F}=91.38)$, group effect .i.e. assertiveness skills training to decrease staffs' stress is significant. It means that difference between two test and control groups was significant. As a result, the second hypothesis is confirmed; i.e. assertiveness skills training have an effect on the decrease of stress in the employees of the Qaen city emergency medical center. Thus, it is observed that assertiveness skills training are effective in increasing the amount of assertiveness and 
reducing amount of stress before and after training.

\section{Discussion}

The results of this study showed that assertiveness skills training was effective on the decrease of stress and also the increase of assertiveness of staffs at emergency medical center; i.e. after removing the effect of the pretest, there was a significant difference between the mean scores of stress and assertiveness of staffs working at emergency medical center. So, research hypothesis as the effect of assertiveness skills training on the decrease of stress and the increase of assertiveness of staffs at emergency medical center of Qaen city were confirmed.

In comparing this research with similar studies, we can refer to research [15] which its results indicated a positive impact of the role of group counseling in raising self-esteem. Also, [16] in the research accomplished on the effect of assertiveness training on the assertiveness and self-esteem of low-assertive employees, it was found that the assertiveness training in a cognitive way will significantly increase the assertiveness and self-esteem of the staffs.

Rahimi et al. in his research on the effect of assertiveness training on social skills, social anxiety and self-expression in first-year boy students concluded that assertiveness training causes an increase in the social skills, selfexpression and the decrease of social anxiety [17]. Mazloom et al. in a study to investigate the assertiveness skills training on the level of interpersonal conflicts among 60 nurses at Imam Reza Hospital during a two-day workshop found that assertiveness skills training is effective in reducing the level of interpersonal conflicts among nurses. Therefore, it can be suggested that assertiveness skill training program is used in nurses' in-service training courses in order to train nurses and equip them for confronting and correct management of conflicts [18].

In another study, Shilling used the assertiveness training to treat the school leaving and confinement and found positive results [19].

Hojat et al investigated the effect of assertiveness skill group training on the selfesteem and loneliness in female students with addicted parents. Findings showed that there is a significant difference between test and control groups i.e. assertiveness skills training significantly changed the mean scores of self-esteem and loneliness in the test group compared to the control group [20].

Bahrami and Velop used 6-session assertiveness training for people without assertiveness and this group showed a significant difference compared to the control group $[21,22]$. One of the major problems of people is the inability for self-expression which leads to diffidence followed by aloofness and aggression and lack of maturity behavior. All these issues can have a significant impact on their social compatibility. Any isolation and aloofness can have many reasons, including not having enough time to practice individual skills, failing to observe the appropriate pattern, feeling guilty and sometimes learning inappropriate behaviors. These are obstacles preventing the learning of social skills and ultimately causing lack of self-confidence and decrease in self-esteem [22].

Assertive or self-expression training is a semi-structured learning approach which is characterized by the emphasis on acquiring self-expression skills through practice and self-expression skills enable the individual to stand up for his beliefs and rights [21].

Volpibelieved that the self-expression behavior is considered as an appropriate emotional expression rather than anxiety versus other people. His goal was to reduce social anxiety and social mutual fear, which prevented the man from expressing himself. He taught the self-expression based on the principle of reciprocal inhibition. This principle states that if an anxiety inhibitor reaction can be created in the presence of anxiety stimulus, the link between that stimulus and anxiety becomes weak. He trained his patients to respond in social situations with anger, love, or any emotion that prevents anxiety. He stimulated patients by playing the role of tension-creating situations. Then he taught 
them to express feelings other than anxiety in the role play. Whenever a patient performs a scene successfully, the link between the social stimulus and the anxiety reaction becomes weaker until the anxiety completely disappears. Then the trained person can transfer his training to real-life situations [22,23].

This research had some limitations. Due to limited statistical population of this study, the results of this study cannot be extended to communities in other cities, especially cities with cultural, ethnic, and educational characteristics that are very different from Qaen city and it is necessary to be very cautious in generalizing the results of this research. In addition, this research refers to the effect of the assertiveness methods among the staffs and shows that this training program is effective for employees but this research does not make it clear whether these methods can be effective for all individuals with different circumstances and in different situations or not?

\section{Conclusion}

Educational and therapeutic methods of assertiveness are numerous. Some of them are complementary and others are considered independent methods. These methods include rational reconstruction, desensitization, behavior exercise, role-playing, modeling, verbal and video feedback, Providing educational videos, problem-solving, guidance, reinforcement, stop thinking, educating appropriate solutions and different behavioral styles for the homework assignment, guidance, reinforcement, stop thinking and so on. But the way in which this study was done with regard to theories and educational works was the self-expression training through the appropriate solution training and different behavioral styles.

\section{Acknowledgments}

We would like to thank all the people who helped us in performing this research.

\section{Contribution}

Study design: HM, MAN
Data collection and analysis: SSD

Manuscript preparation: HM, MAN, SSD

\section{Conflict of Interest}

The authors declare that they have no competing.

\section{Funding}

The authors received no financial support for the research, authorship and/ or publication of this article.

\section{References}

1- Vandenbos GR. APA dictionary of psychology. Washington, DC, US: American psychological association; 2007

2- Pope AW, McHale SM, Craighead WE. Self-esteem enhancement with children and adolescents. Translated by Parisa Tajalli. Tehran: Roshd; 2006.

3- Bolton R. Psychology of Human Relations (people skills). Translated by Hamid Reza Sohrabi and Afsaneh Hayat Roshanaei. Tehran: Roshd; 2007.

4-Raudsepp E. How assertive are you. Supervision 2005; 66: 18-20.

5- Van Gundy, K. Gender, the assertion of autonomy, and the stress process in young adulthood. Soc Psychol Q2002; 65(4): 346-63.

6- Lounsbury JW, Loveland JM, Sundstrom ED, Gibson LW, Drost AW, Hamrick FL. An investigation of personality traits in relation to career satisfaction. $J$ Career Assess2003; 11(3): 287-308.

7- Bishop S. Develop your assertiveness. London: Kogan page; 2006.

8- Hennessy K. Assertive communication. Faculty and employee assistance program; 2004.

9- Hargie O, Dickson D. Skilled interpersonal communication: research, theory and practice. London: Routledge publishing; 2004.

10- Lotfi Kashani F, Vaziri Sh. Child psychological. Tehran: Arasbaran publications; 2004.

11-Lin YR, Shiah IS, Chang YC, Lai TJ, Wang KY, Chou KR. Evaluation of an assertiveness training program on nursing and medical students' assertiveness, selfesteem, and interpersonal communication satisfaction. Nurse Educ Today2004; 24(8): 656-65.

12- Piri L. The relationship between identity styles and life skills (expression ability and coping with stress) in pre-school students in Tehran (82-83). [Thesis]. Faculty of psychology and educational sciences. Tehran: Tarbiatamol university; 2004.

13- Ghobari Bonab B, Hejazi M. Relationship among assertiveness, self-esteem and academic achievement 
in gifted and regular school students. Journal of Exceptional Children2007; 7 (3) :299-316

14- Attar H. Investigating relationships of job stress with job satisfaction and mental health of industrial complex staff. Journal of Andishe va Raftar1995; 2(3): 69-78.

15- Adib N. Investigating the role of group counseling in raising adolescents' self-esteem. [Thesis]. Tehran: Allameh Tabatabai university 1995.

16- Abbasinia M. The effect of teaching and learning on the self-esteem of low-couraged children in the district of Qom (78-77). [Thesis]. Tehran: Allameh tabatabaee university 1999.

17- Rahimi G, Haghighi J, Mehrabizadeh Honarmand $\mathrm{M}$, Beshlideh $\mathrm{K}$. The effect of group assertive training on social anxiety, social skills and assertiveness of male first grade high school students in Shiraz. Journal of Educational and Psychology2006; 13(1): 111-24.

18- Mazlom SR, Motahari M, Maghsoudi Poorzaid badi
S, Asgharipour N. Effect of assertiveness training on nurses' interpersonal conflicts. Journal of Mazandaran University of Medical Sciences 2015; 25(124) :107-18 19- Shilling L. Perspectives on counselin theories. translation: Arian Kh. Tehran: Ettelaat publishing; 2000. 20- Hojjat SK, Sajedi M, Rezaei M, Noruzi Khalili M, Rahimi A, Ein Beigi E. The effect of Assertiveness skill training on self-esteem and loneliness of female students with addicted parents. Journal of North Khorasan University of Medical Sciences2017; 8(4): 675-84

21- Bahrami F. Comparing the methods of assertiveness to low-level students of high school girl with group counseling and individual counseling in Isfahan. [Thesis]. Tehran: Allameh Tabatabai University, 1996. 22- Wolpe J. Objective psychotherapy of the neveroses. South African Medical Journal1992; 28: 825-9.

23- Fenstrerheim H, Weber, J. the assertiveness training. Translator: Abbas Chini, Tehran: Alborz, 2003.

\footnotetext{
Copyright(C) 2016 ASP Ins. This open-access article is published under the terms of the Creative Commons Attribution-NonCommercial 4.0 International License which permits Share (copy and redistribute the material in any medium or format) and Adapt (remix, transform, and build upon the material) under the Attribution-NonCommercial terms.
} 